Cochrane Database of Systematic Reviews

\title{
En-bloc resection versus conventional transurethral resection for patients with non-muscle-invasive bladder cancer (Protocol)
}

van Putten K, Vernooij RWM, Meijer RP, Zhu X

van Putten K, Vernooij RWM, Meijer RP, Zhu X.

En-bloc resection versus conventional transurethral resection for patients with non-muscle-invasive bladder cancer.

Cochrane Database of Systematic Reviews 2019, Issue 11. Art. No.: CD013473.

DOI: 10.1002/14651858.CD013473.

www.cochranelibrary.com

En-bloc resection versus conventional transurethral resection for patients with non-muscle-invasive bladder 
TABLE OF CONTENTS

HEADER 1

ABSTRACT

BACKGROUND

OBJECTIVES

METHODS

ACKNOWLEDGEMENTS

REFERENCES

ADDITIONAL TABLES

APPENDICES

CONTRIBUTIONS OF AUTHORS

DECLARATIONS OF INTEREST

SOURCES OF SUPPORT 
[Intervention Protocol]

\section{En-bloc resection versus conventional transurethral resection for patients with non-muscle-invasive bladder cancer}

Kim van Putten ${ }^{1}$, Robin WM Vernooij ${ }^{2}$, Richard P Meijer ${ }^{1}$, Xiaoye Zhu ${ }^{3}$

1Department of Oncological Urology, University Medical Center Utrecht, Utrecht, Netherlands. 2Department of Nephrology and Hypertension and Julius Center for Health Sciences and Primary Care, University Medical Center Utrecht, Utrecht, Netherlands. 3Department of Urology, Radboudumc, University Medical Center, Nijmegen, Netherlands

Contact address: Kim van Putten, Department of Oncological Urology, University Medical Center Utrecht, Heidelberglaan 100, Utrecht, 3584 CX, Netherlands. k.vanputten-2@umcutrecht.nl, kimmetje_p@hotmail.com.

Editorial group: Cochrane Urology Group

Publication status and date: New, published in Issue 11, 2019.

Citation: van Putten K, Vernooij RWM, Meijer RP, Zhu X. En-bloc resection versus conventional transurethral resection for patients with non-muscle-invasive bladder cancer. Cochrane Database of Systematic Reviews 2019, Issue 11. Art. No.: CD013473. DOI: 10.1002/14651858.CD013473.

Copyright (c) 2019 The Cochrane Collaboration. Published by John Wiley \& Sons, Ltd.

\section{A B S T R A C T}

This is a protocol for a Cochrane Review (Intervention). The objectives are as follows:

To assess the effects of en-bloc resection compared with conventional transurethral resection for the best approach of bladder cancer in patients with non-muscle-invasive bladder cancer. 


\section{B A C K G R O U N D}

\section{Description of the condition}

Urothelial bladder cancer causes significant morbidity and mortality (Burger 2013). Worldwide, bladder cancer in both sexes is the 11th most commonly diagnosed cancer (7th in men and 19th in women). The global age-standardized incidence rate (per 100,000 person/years) is 9.0 for men and 2.2 for women. Bladder cancer is the 14th leading cause of cancer deaths worldwide. The age-standardized mortality rate (per 100,000 person/years) was 3.2 for men versus 0.9 for women in 2012 (Bray 2018).

Bladder cancer incidence and mortality rates vary worldwide, mainly due to differences in risk factors, detection, and diagnostic practices, and availability of treatments. However, these variations are partly caused by the different methodologies used in data collection (differences in coding and registration practices (Antoni 2017), and the subsequent quality of the data (Burger 2013). The decrease in incidence of and mortality due to bladder cancer seen in some, mostly low- or middle-income countries, possibly reflects the reduced impact of causative agents (Bosetti 2011; Chavan 2014; Jemal 2010). Overall an increase in incidence is seen, possibly due to an aging global population (Kramer 2014; Chavan 2014), and improved detection mechanisms and screening (Cumberbatch 2015). As the second most common urological tumour, bladder cancer represents a growing healthcare problem, accounting for a large part of total healthcare costs worldwide (Brausi 2002; Kramer 2015; Sievert 2009). Moreover, bladder cancer confers the largest financial burden per patient of all types of malignant tumours (Cooksley 2008).

The most important risk factor for bladder cancer, accounting for approximately $50 \%$ of cases, is tobacco smoking (Babjuk 2016; Cumberbatch 2016). Other well-established risk factors for bladder cancer include: 1) infection with Schistosoma haematobium (Burger 2013), specifically a chronic endemic cystitis based on recurrent infection with the parasitic trematode; and 2) occupational exposure to aromatic amines and polycyclic aromatic hydrocarbons and chlorinated hydrocarbons, which are excreted renally (Chavan 2014; Colt 2014; Freedman 2011; van Osch 2016). The latter concerns mainly occupations in the industrial setting, which process paint, dye, metal, and petroleum products. Work-safety guidelines applied in industrial plants have reduced these occupational exposure risks, resulting in a similar incidence of bladder cancer compared with the general population (Babjuk 2016). Dietary patterns, environmental pollution, and genetic predisposition are other suggested and suspected risk factors for bladder cancer (Figueroa 2016; Steinmaus 2014; Vieira 2015). In most parts of the world outside of Africa, high tobacco consumption is the major cause of bladder cancer; while in most parts of Africa, infection with S haematobium is the predominant cause (Chavan 2014).

Bladder cancer can be differentiated between transitional cell carcinoma ( $90 \%$ of cases) and squamous cell carcinoma of the bladder (Witjes 2018). Tobacco smoking is associated with transitional cell carcinoma, while Shaematobium infection causes mainly squamous cell carcinoma (Burger 2013).

Approximately three-quarters of newly diagnosed bladder cancers present with a non-muscle-invasive disease, being confined to the mucosa (stage Ta, carcinoma in situ) or submucosa (T1) (Babjuk 2016). This percentage shows a rise in a younger population of pa- tients (< 40 years of age) (Compérat 2015). Compared to muscle invasive bladder cancer (T2-4), patients with non-muscle-invasive bladder cancer, being TaT1 or carcinoma in situ (CIS), are more prevalent due to the higher incidence and better outcome due to a lower cancer-specific mortality (Sylvester 2005; Witjes 2018).

The 2017 TNM classification is used for staging (Table 1). For grading, both 1973 and 2004 World Health Organization (WHO) grading classifications are used. Non-muscle-invasive bladder cancer is defined as confined to the mucosa (Babjuk 2016; Babjuk 2018a; Sobin 2009).

After primary assessment of bladder cancer, a transurethral resection is the gold standard strategy of choice. The goal of this procedure is complete removal of the tumour and adequate pathological classification with the lowest possible morbidity to the patient (Babjuk 2016; Babjuk 2018b).

\section{Description of the intervention}

Traditional transurethral resection is performed systematically in fractions (exophytic part of the tumour, the underlying bladder wall, and the edges of the resection area) using an electrical wire loop via a resectoscope (Babjuk 2016). In contrast, a basic principle of oncological surgery is to remove the entire lesion (Hurle 2016). En-bloc tumour resection, which is not a new concept, differs from traditional resection since the goal is not to fragment the tumour. It can be performed using different energy sources. The technique is performed using electrical (monopolar or bipolar), laser cautery (holmium/thulium), and more recently water-jet. Water-jet resection is a novel technique in transurethral resection, and uses a water-jet as a resection tool instead of a laser beam (Islas-García 2016; Kramer 2011; Migliari 2015; Zhang 2015). En-bloc resection is believed to be a safe, effective, feasible, and reliable technique. Some even believe it to be superior, or at least non-inferior, in accuracy compared to conventional transurethral resection (Hurle 2016; Kramer 2017; Migliari 2015). Nowadays both methods, en-bloc resection and conventional transurethral resection, are used with a worldwide variation based on surgeons' preference. The strategy of resection depends on size and location of the lesion. European guidelines recommend performing a resection en-bloc or in fractions, not specifying in what case to choose what strategy (Babjuk 2016). Although randomized trials have been undertaken for this comparison, high-quality systematic reviews including an assessment of the quality of the evidence (e.g. GRADE approach) are lacking. The results of a Cochrane Review might help to determine in which cases one or other technique is preferred.

\section{Adverse effects of the intervention}

Transurethral bladder tumour resection is one of the most commonly performed procedures by practicing urologists and residents of urology (Richards 2014). A possible major complication is bladder perforation, in some cases caused by an obturator nerve reflex. Other complications include bleeding, urinary tract infection, and urethral stricture (Collado 2000; Traxer 2004). Novel techniques are introduced frequently but should be studied, reviewed carefully, and only applied when added value is established. The downside of applying a novel technique is its learning curve (Richards 2014). 


\section{How the intervention might work}

The rationale of preference of en-bloc resection over conventional resection is a reduction of tumour recurrence rate and progression rate because of better pathological classification (meaning inclusion of detrusor muscle in the specimen) and avoidance of seeding of microscopic floating tumour cells, which may occur during conventional resection (Kramer 2014).

Furthermore, by using the en-bloc technique, a more complete resection may be performed and thereby reduce the rate of re-resection (Mariappan 2010), usually required when sampling does not include muscularis propria. In line with this avoidance of seeding of microscopic floating tumour cells and inadequate sampling without musculus propria, we expect fewer complications because of just one single operation instead of multiple procedures and subsequently necessary anaesthetics, shorter operation time and hospitalization time, ultimately leading to lower general healthcare costs and higher quality of life (Richards 2014). Routinely guideline recommended re-resections for high-grade tumours.

\section{Why it is important to do this review}

En-bloc resection might offer better staging of bladder tumours and may result in less recurrence or progression, or both. Furthermore, en-bloc resection could result in fewer re-resections because of more a radical primary resection (Kramer 2017). The EAU Guideline has defined en-bloc resection as 'feasible' in selected tumours (Babjuk 2018a). Benefits in diagnostic accuracy, reduction of recurrences, decrease of complications, and, indirectly, reduction of healthcare costs associated with management of non-muscle-invasive bladder cancer may be elucidated with this review.

\section{OB JECTIVES}

To assess the effects of en-bloc resection compared with conventional transurethral resection for the best approach of bladder cancer in patients with non-muscle-invasive bladder cancer.

\section{METHODS}

\section{Criteria for considering studies for this review}

\section{Types of studies}

We will include studies regardless of their publication status or language of publication. We will include randomized controlled trials (RCTs) or quasi-RCTs. Full reports and other types of reports, such as conference proceedings, are eligible for inclusion. We will exclude cross-over designs due to the nature of the intervention and control.

We will include studies that meet the inclusion criteria but do not report one or more of our primary or secondary outcomes.

\section{Types of participants}

We will include adults of both genders with suspected non-muscle-invasive bladder cancer. We will exclude patients with suspected $\mathrm{T} 3 / 4, \mathrm{~N}+$, or $\mathrm{M}+$ disease (Table 1 ). We will contact study authors if we require further clarification to determine the health status of the included patients. Should we identify studies in which only a subset of participants are relevant to this review, we will include such studies if data are available separately for the relevant subset.

\section{Types of interventions}

We plan to investigate the following comparisons of experimental intervention versus comparator intervention. We will investigate the difference between bipolar and monopolar resection if necessary.

\section{Experimental interventions}

- En-bloc resection (including electrical, laser (holmium/thulium) and water-jet hybrid knife resection).

\section{Comparator interventions}

- Conventional transurethral resection (electrical resection).

\section{Comparisons}

- En-bloc resection versus conventional transurethral resection.

\section{Types of outcome measures}

\section{Primary outcomes}

- Tumor recurrence (dichotomous outcome).

- Serious adverse events (Clavien grade 4-5) (dichotomous outcome).

\section{Secondary outcomes}

- Progression rate (dichotomous outcome).

- Presence of detrusor muscle in histopathological sample (dichotomous outcome).

- Re-resection (dichotomous outcome).

- Adverse events (Clavien grade 1-3) (dichotomous outcome).

\section{Method and timing of outcome measurement}

The main time point of interest is 'end of trial' defined as the point of time with the longest follow-up duration from time of randomization. We will also extract and present the outcome data reported at other time points after randomization, if applicable.

- Tumor recurrence: defined as the proportion of patients with tumour recurrence that is identified with visual or pathological confirmation by three years after the procedure.

- Progression rate: defined as the proportion of patients that are identified as having progression of their tumour (upstaging) (defined as progression in T-stadium according to 2009 TNM (Tumor-Node-Metastasis) classification of urinary bladder cancer (Sobin 2009)) or upgrading (defined as progression in WHO grading of 1973 (Mostofi 1973) and 2004 (Eble JN) by three years after the procedure). Any form of progression, non-muscle-invasive to muscle invasive, but also CIS [carcinoma in situ] and low to high-grade progression will be considered as progression.

- Adverse events: defined as the number of patients that experience adverse events, including excessive bleeding, bladder perforation, need for transfusion, re-operation, re-admission, longer duration of indwelling catheter, urinary tract infection, and urethral stricture at the end of the trial. The adverse events are scored in grade 4 to 5 or grade 1 to 3 according to the Common Terminology Criteria for Adverse Events (CTCAE) (National Cancer Institute 2017).

- Presence of detrusor muscle in histopathological sample: defined as the proportion of patients identified as having detrusor muscle in their histopathological sample at the end of the trial. 
- Re-resection: defined as the proportion of patients that require a re-resection within three months of TURBT [transurethral resection bladder tumor] (due to concerns about incomplete resection).

To assess the certainty of the evidence for imprecision in our 'Summary of findings' tables (Johnston 2013), we will try to find any published information about a clinically important difference for the dichotomous outcomes (tumour recurrence, progression rate, presence of detrusor muscle in histopathological sample, re-resection, and adverse events). However, if this is not available, we will use a relative risk reduction (RRR) or a risk ratio (RR) of at least $25 \%$, based on guidance in Guyatt 2011b.

\section{Search methods for identification of studies}

We will perform a comprehensive search with no restriction on the language of publication or publication status. We plan to rerun searches within three months prior to anticipated publication of the review.

\section{Electronic searches}

We will search the following sources from inception of each database (Appendix 1).

- CENTRAL.

- MEDLINE (via PubMed/Ovid).

- Embase (via Ovid).

- Scopus.

- Google Scholar.

- Web of Science.

We will also search the following.

- ClinicalTrials.gov (www.clinicaltrials.gov/).

- World Health Organization (WHO) International Clinical Trials Registry Platform (ICTRP) search portal (apps.who.int/trialsearch/).

If we detect additional relevant keywords during any of the electronic or other searches, we will modify the electronic search strategies to incorporate these terms and will document the changes.

\section{Searching other resources}

We will try to identify other potentially-eligible trials or additional publications by searching the reference lists of retrieved included trials, reviews, meta-analyses, and clinical guidelines. We will also contact study authors of included trials to identify any further studies that we may have missed. We will search abstract proceedings of relevant meetings, including European Association of Urology (EAU), American Urological Association (AUA), and ASCO-GU of the preceding three years for unpublished studies.

\section{Data collection and analysis}

\section{Selection of studies}

We will use reference management software to identify and remove potential duplicate records (EndNote 2016). Two review authors (KvP, XZ) will independently assess the titles, abstracts, or both, of records identified in the search against the predefined inclusion criteria to determine which studies we should assess further.
Two review authors (KvP, XZ) will investigate all potentially-relevant records as full-text, will map records to studies, and will classify studies as included studies, excluded studies, studies awaiting classification, or ongoing studies in accordance with the criteria for each provided in the Cochrane Handbook for Systematic Reviews of Interventions (Higgins 2011a; Higgins 2017). We resolve any discrepancies through discussion or arbitration by a third review author (RM). If resolution of a disagreement is not possible, we will designate the study as 'awaiting classification' and we will contact study authors for clarification. We will document reasons for exclusion of studies that may have reasonably been expected to be included in the review in a 'Characteristics of excluded studies' table. We will present an adapted PRISMA flow diagram showing the process of study selection (Liberati 2009).

\section{Data extraction and management}

We will develop a dedicated data abstraction form that we will pilot test ahead of time based on the recommendations of the Cochrane Handbook for Systematic Reviews of Interventions (Higgins 2017). For studies that fulfil the inclusion criteria, two review authors (KvP, XZ) will independently abstract the following information, which we will record in the 'Characteristics of included studies' table.

- Study design.

- Study dates (if dates are not available the this was reported as such).

- Study settings and country.

- Participant inclusion and exclusion criteria.

- Participant details, baseline demographics.

- The number of participants by study and by study arm.

- Details of relevant experimental and comparator interventions such as dose, route, frequency, and duration.

- Definitions of relevant outcomes, and method and timing of outcome measurement as well as any relevant subgroups.

- Study funding sources.

- Declarations of interest by primary investigators.

We will extract outcomes data relevant to this Cochrane Review as needed for calculation of summary statistics and measures of variance. For dichotomous outcomes, we will attempt to obtain numbers of events and totals for population of a $2 \times 2$ table, as well as summary statistics with corresponding measures of variance. For continuous outcomes, we will attempt to obtain means and standard deviations or data necessary to calculate this information.

We will resolve any disagreements by discussion, or, if required, by consulting a third review author (RV).

We will provide information, including trial identifier, about potentially relevant ongoing studies in the 'Characteristics of ongoing studies' table.

We will attempt to contact authors of included studies to obtain key missing data as needed.

\section{Dealing with duplicate and companion publications}

In the event of duplicate publications, companion documents, or multiple reports of a primary study, we will maximize yield of information by mapping all publications to unique studies and collating all available data. We will use the most complete dataset aggregat- 
ed across all known publications. In case of doubt, we will give priority to the publication that reports the longest follow-up associated with our primary or secondary outcomes.

\section{Assessment of risk of bias in included studies}

Two review authors (KvP, XZ) will independently assess the risk of bias of each included study. We will resolve disagreements by consensus or by consulting a third review author (RV).

We will assess risk of bias using Cochrane's 'Risk of bias' assessment tool (Higgins 2017; Higgins 2011b). We will assess the following domains:

- Random sequence generation (selection bias).

- Allocation concealment (selection bias).

- Blinding of participants and personnel (performance bias).

- Blinding of outcome assessment (detection bias).

- Incomplete outcome data (attrition bias).

- Selective reporting (reporting bias).

- Other sources of bias.

We will judge risk of bias domains as 'low risk', 'high risk', or 'unclear risk' and will evaluate individual bias items as described in the Cochrane Handbook for Systematic Reviews of Interventions (Higgins 2011b; Higgins 2017). We will present a 'Risk of bias' summary figure to illustrate these findings.

For selection bias (random sequence generation and allocation concealment) and reporting bias (selective reporting), we will evaluate the risks of bias at a trial level.

For performance bias (blinding of participants and personnel), we will evaluate the risk of bias separately for each outcome, and will group outcomes according to whether measured when reporting our findings in the 'Risk of bias' tables.

We also will assess attrition bias (incomplete outcome data) on an outcome-specific basis, and group outcomes with like judgements when reporting our findings in the 'Risk of bias' tables.

We will further summarize the risk of bias across domains for each outcome in each included study, as well as across studies and domains for each outcome.

We define the following endpoints as subjective outcomes:

- Tumour recurrence.

- Serious adverse events (grade 4-5).

- Progression rate.

- Presence of detrusor muscle in histopathological sample.

- Re-resection.

- Adverse events (grade 1-3).

\section{Measures of treatment effect}

If we identify at least two included trials that provide data on a given outcome, we will express dichotomous data as risk ratios (RRs) with $95 \%$ confidence intervals (Cls). For continuous outcomes measured using the same scale, we will use mean difference (MD) values with $95 \% \mathrm{Cls}$. In the case of continuous outcomes measuring the same concept but using different measurement scales, we will express the data as standardized mean differences with $95 \% \mathrm{Cls}$.

\section{Unit of analysis issues}

The unit of analysis will be the individual participant. If we identify trials with more than two intervention groups for inclusion, we will handle these in accordance with guidance provided in the Cochrane Handbook for Systematic Reviews of Interventions (Higgins 2011c; Higgins 2017).

\section{Dealing with missing data}

We will contact the study authors to obtain missing data, if possible, and will perform intention-to-treat (ITT) analyses if data are available; otherwise we will perform available case analyses. We will investigate attrition rates, e.g. drop-outs, losses to follow-up, and withdrawals, and will critically appraise issues of missing data. We do not plan to impute missing data.

\section{Assessment of heterogeneity}

In the event of excessive heterogeneity unexplained by subgroup analyses, we will not report outcome results as the pooled effect estimate in a meta-analysis but will provide a narrative description of the results of each study.

We will assess heterogeneity (inconsistency) through visual inspection of the forest plots to assess the amount of overlap of $\mathrm{Cls}$, and the $1^{2}$ statistic, which quantifies inconsistency across studies to assess the impact of heterogeneity on the meta-analysis (Higgins 2002; Higgins 2003); we will interpret the $\mathrm{I}^{2}$ statistic as follows (Covidence; Deeks 2011):

- $0 \%$ to $40 \%$ : may not be important.

- $30 \%$ to $60 \%$ : may indicate moderate heterogeneity.

- $50 \%$ to $90 \%$ : may indicate substantial heterogeneity.

- $75 \%$ to $100 \%$ : considerable heterogeneity.

If we identify heterogeneity, we will attempt to determine possible reasons for it by examining individual study and subgroup characteristics.

\section{Assessment of reporting biases}

We will attempt to obtain study protocols to assess for selective outcome reporting. If we include 10 studies or more investigating a particular outcome, we will use funnel plots to assess small study effects.

Several explanations can be offered for the asymmetry of a funnel plot, including true heterogeneity of effect with respect to trial size, poor methodological design (and hence bias of small trials), and publication bias. We therefore will interpret results with caution (Sterne 2011).

\section{Data synthesis}

We will perform all data synthesis using Review Manager 5 (Review Manager 2014). Unless there is sufficient evidence for homogeneous effects across studies, we will summarize data using a random-effects model. We will interpret random-effects meta-analyses with due consideration of the whole distribution of effects. In addition, we will perform statistical analyses according to the statistical guidelines in the Cochrane Handbook for Systematic Reviews of Interventions (Higgins 2017; Review Manager 2014). For dichotomous outcomes, we will use the Mantel-Haenszel method; for continuous outcomes, we will use the inverse variance method. 


\section{Subgroup analysis and investigation of heterogeneity}

We expect the following characteristics might introduce clinical heterogeneity, and plan to perform subgroup analyses with investigation of interactions:

- Based on different techniques of en-bloc resection (electrical versus laser versus water-jet hybrid knife). We will perform the subgroup analyses limited to the primary outcomes.

We will use the test for subgroup differences in Review Manager 5 to compare subgroup analyses if there is a sufficient number of included studies (Hozo 2005; Review Manager 2014).

\section{Sensitivity analysis}

We plan to perform sensitivity analyses in order to explore the influence of the following factors (when applicable) on effect sizes:

- Restricting the analysis by taking into account risk of bias, by excluding studies at 'high risk' or 'unclear risk'.

\section{'Summary of findings' table}

\section{Main outcomes for 'Summary of findings' table}

We will present a 'Summary of findings' table and will report the following outcomes, which are listed according to priority.

- Tumour recurrence.

- Serious adverse events (grade 4-5).
- Progression rate.

- Presence of detrusor muscle in histopathological sample.

- Re-resection.

- Adverse events (grade 1-3).

We will assess and present the quality of the evidence for each outcome according to the GRADE approach, which takes into account five criteria related to internal validity (risk of bias, inconsistency, imprecision, publication bias) and also to external validity (such as directness of results) (Guyatt 2008). For each comparison, two review authors (KvP, XZ) will independently assess the quality of evidence for each outcome as either 'high', 'moderate', 'low', or 'very low' using GRADEpro GDT software (GRADEpro GDT). We will resolve any discrepancies by consensus, or, if necessary, a third review author (RV) will arbitrate. For each comparison, we will present a summary of the evidence for the main outcomes in a 'Summary of findings' table, which will provide key information about the best estimate of the magnitude of the effect in relative terms and absolute differences for each relevant comparison of alternative management strategies; numbers of participants and studies addressing each important outcome; and the rating of the overall confidence in effect estimates for each outcome (Guyatt 2011a; Schünemann 2011). If meta-analysis is not possible, we will present results in a narrative 'Summary of findings' table.

\section{ACKN O WLEDGEMENTS}

None 


\section{R E F E R E N C E S}

\section{Additional references}

\section{Antoni 2017}

Antoni S, Ferlay J, Soerjomataram I, Znaor A, Jemal A, Bray F. Bladder cancer incidence and mortality: a global overview and recent trends. European Urology 2017;71(1):96-108.

\section{Babjuk 2016}

Babjuk M, Böhle A, Burger M, Capoun O, Cohen D, Compérat EM, et al. EAU guidelines on non-muscle-invasive urothelial carcinoma of the bladder: update 2016. European Urology 2017;71(3):447-61.

\section{Babjuk 2018a}

Babjuk M, Burger M, Compérat E, Gontero P, Mostafid AH, Palou J, et al. EAU guideline non-muscle-invasive bladder cancer. 2017. assessed 25 June 2018. Arnhem: EAU Guidelines Office.

\section{Babjuk 2018b}

Babjuk M, Burger M, Compérat E, Gontero P, Mostafid A, Palou J, et al. EAU guidelines on non-muscle-invasive urothelial carcinoma of the bladder: update 2018. assessed 25 June 2018. Arnhem: EAU Guidelines Office.

\section{Bosetti 2011}

Bosetti T, Bertuccio P, Chatenoud L, Negri E, La Vecchia C, Levi F. Trends in mortality from urologic cancers in Europe, 1970-2008. European Urology 2011;60(1):1-15.

\section{Brausi 2002}

Brausi M, Collette L, Kurth K, van der Meijden AP, Oosterlinck W, Witjes JA, et al. Variability in the recurrence rate at first follow-up cystoscopy after TUR in stage Ta T1 transitional cell carcinoma of the bladder: a combined analysis of seven EORTC studies. European Urology 2002;41(5):523-31.

\section{Bray 2018}

Bray F, Ferlay J, Soerjomataram I, Siegel RL, Torre LA, Jemal A. Global Cancer Statistics 2018: GLOBOCAN Estimates of Incidence and Mortality Worldwide for 36 Cancers in 185 Countries. CA Cancer J Clin 2018;68(6):394-424. [DOI: 10.3322/ caac.21492]

\section{Brierley 2017}

Brierley JD, Gospodarowicz MIDDENKWAB, Wittekind C. TNM Classification of Malignant Tumours, 8th Edition. WileyBlackwell, 2017. [ISBN: 978-1-119-26357-9]

\section{Burger 2013}

Burger M, Catto JW, Dalbagni G, Grossman HB, Herr H, Karakiewicz P, et al. Epidemiology and risk factors of urothelial bladder cancer. Eur Urol, 2013. European Urology 2013;63(2):234-41.

\section{Chavan 2014}

Chavan S, Bray F, Lortet-Tieulent J, Goodman M, Jemal A. International variations in bladder cancer incidence and mortality.. European Urology 2014;66(1):59-73.

\section{Collado 2000}

Collado A, Chéchile GE, Salvador J, Vicente J. Early complications of endoscopic treatment for superficial bladder tumors. Journal of Urology 2000;164(5):1529-32.

\section{Colt 2014}

Colt S, Friesen MC, Stewart PA, Donguk P, Johnson A, Schwenn M, et al. A case-control study of occupational exposure to metalworking fluids and bladder cancer risk among men. Occupational and Environmental Medicine 2014;71(10):667-74.

\section{Compérat 2015}

Compérat E, Larré S, Roupret M, Neuzillet Y, Pignot G, Quintens $\mathrm{H}$, et al. Clinicopathological characteristics of urothelial bladder cancer in patients less than 40 years old. Virchows Archiv 2015;466(5):589-94.

\section{Cooksley 2008}

Cooksley C, Avritscher E, Grossman B, Sabichi A, Dinney C, Pettaway $C$, et al. Clinical model of cost of bladder cancer in the elderly. Urology 2008;71(3):519-25.

\section{Covidence [Computer program]}

Veritas Health Innovation. Covidence. Version accessed 10 December 2018. Melbourne, Australia: Veritas Health Innovation, 2018.

\section{Cumberbatch 2015}

Cumberbatch M, Cox A, Teare D, Catto JW. Contemporary occupational carcinogen exposure and bladder cancer: a systematic review and meta-analysis. JAMA Oncology 2015;1(9):1282-90.

\section{Cumberbatch 2016}

Cumberbatch M, Rota M, Catto J, La Vecchia C. The role of tobacco smoke in bladder and kidney carcinogenesis: a comparison of exposures and meta-analysis of incidence and mortality risks. European Urology 2016;70(3):458-66.

\section{Deeks 2011}

Deeks JJ, Higgins JPT, Altman DG (editors). Chapter 9: Analysing data and undertaking meta-analyses. In: Higgins JP, Green $\mathrm{S}$, editor(s). Cochrane Handbook for Systematic Reviews of Interventions Version 5.1.0 (updated March 2011). The Cochrane Collaboration, 2011. Available from handbook.cochrane.org.

\section{Eble JN}

Eble JN, Sauter G, Epstein JI, Sesterhenn IA. Tumours of the urinary system: non-invasive urothelial neoplasias. WHO classification of tumors of the urinary system and male genital organs. Lyon: IARCC Press, 2004.

\section{EndNote 2016 [Computer program]}

Clarivate Analytics. EndNote. Version 7.5. Clarivate Analytics, 2016.

\section{Figueroa 2016}

Figueroa JD, Middlebrooks CD, Banday AR, Ye Y, GarciaClosas M, Chatterjee N, et al. Identification of a novel 
susceptibility locus at $13 q 34$ and refinement of the 20 p12.2 region as a multi-signal locus associated with bladder cancer risk in individuals of European ancestry. Human Molecular Genetics 2016;25(6):1203-14.

\section{Freedman 2011}

Freedman ND, Silverman DT, Hollenbeck AR, Schatzkin A, Abnet CC. Association between smoking and risk of bladder cancer among men and women. JAMA 2011;306(7):737-45.

\section{GRADEpro GDT [Computer program]}

McMaster University (developed by Evidence Prime). GRADEpro GDT. Version assessed 20 July 2018. Hamilton (ON): McMaster University (developed by Evidence Prime), 2018.

\section{Guyatt 2008}

Guyatt GH, Oxman AD, Vist GE, Kunz R, Falck-Ytter Y, Schünemann HJ, et al. GRADE: what is "quality of evidence" and why is it important to clinicians?. BMJ (Clinical Research Ed.) 2008;336(7651):995-8. [DOI: 10.1136/bmj.39490.551019.BE]

\section{Guyatt 2011a}

Guyatt G, Oxman AD, Akl EA, Kunz R, Vist G, Brozek J, et al. GRADE guidelines: 1. Introduction-GRADE evidence profiles and summary of findings tables. Journal of Clinical Epidemiology 2011;64(4):383-94. [DOI: 10.1016/j.jclinepi.2010.04.026]

\section{Guyatt 2011b}

Guyatt GH, Oxman AD, Kunz R, Brozek J, Alonso-Coello P, Rind $D$, et al. GRADE guidelines 6 . Rating the quality of evidence - imprecision. Journal of Clinical Epidemiology 2011;64(12):1283-93.

\section{Higgins 2002}

Higgins JPT, Thompson SG. Quantifying heterogeneity in a meta-analysis. Statistics in Medicine 2002;21(11):1539-58. [DOI: 10.1002/sim.1186]

\section{Higgins 2003}

Higgins JPT, Thompson SG, Deeks JJ, Altman DG. Measuring inconsistency in meta-analyses. BMJ (Clinical Research Ed.) 2003;327(7414):557-60. [DOI: 10.1136/bmj.327.7414.557]

\section{Higgins 2011a}

Higgins JP, Green S, editor(s). Cochrane Handbook for Systematic Reviews of Interventions Version 5.1.0 (updated March 2011). The Cochrane Collaboration, 2011. Available from handbook.cochrane.org.

\section{Higgins 2011b}

Higgins JPT, Altman DG, Sterne JAC (editors). Chapter 8: Assessing risk of bias in included studies. In: Higgins JP, Green S, editor(s). Cochrane Handbook for Systematic Reviews of Interventions Version 5.1.0 (updated March 2011). The Cochrane Collaboration, 2011. Available from handbook.cochrane.org.

\section{Higgins 2011c}

Higgins JPT, Deeks JJ, Altman DG (editors). Chapter 16: Special topics in statistics. In: Higgins JP, Green S, editor(s). Cochrane Handbook for Systematic Reviews of Interventions Version
5.1.0 (updated March 2011). The Cochrane Collaboration, 2011. Available from handbook.cochrane.org.

\section{Higgins 2017}

Higgins JPT, Churchill R, Chandler J, Cumpston MS (editors). Cochrane Handbook for Systematic Reviews of Interventions version 5.2.0 (updated June 2017). The Cochrane Collaboration, 2017. Available from www.training.cochrane.org/ handbook.

\section{Hozo 2005}

Hozo SP, Djulbegovic B, Hozo I. Estimating the mean and variance from the median, range, and the size of a sample. $B M C$ Medical Research Methodology 2005;5:13.

\section{Hurle 2016}

Hurle R, Lazzeri M, Colombo P, Buffi N, Morenghi E, Peschechera R, et al. "En bloc" resection of nonmuscle invasive bladder cancer: a prospective single-center study. Urology 2016;90:126-30.

\section{Islas-García 2016}

Islas-García JJ, Campos-Salcedo JG, López-Benjume BI, Torres-Gómez JJ, Aguilar-Colmenero J, Martínez-Alonso IA, et al. Surgical technique for en bloc transurethral resection of bladder tumour with a Hybrid Knife. Actas Urologica Espagna 2016;40(4):263-7.

\section{Jemal 2010}

Jemal A, Siegel R, Xu J, Ward E. Cancer statistics 2010. CA: a Cancer Journal for Clinicians 2010;60(5):277-300.

\section{Johnston 2013}

Johnston BC, Patrick DL, Busse JW, Schünemann HJ, Agarwal A, Guyatt GH. Patient-reported outcomes in meta-analyses--Part 1: assessing risk of bias and combining outcomes. Health and Quality of Life Outcomes 2013;11:109.

\section{Kramer 2011}

Kramer MW, Bach T, Wolters M, Imkamp F, Gross AJ, Kuczyk MA, et al. Current evidence for transurethral laser therapy of nonmuscle invasive bladder cancer. World Journal of Urology 2011;29(4):433-42.

\section{Kramer 2014}

Kramer MW, Abdelkawi IF, Wolters M, Bach T, Gross AJ, Nagele U, et al. Current evidence for transurethral en bloc resection of non-muscle-invasive bladder cancer.. Minimal Invasive Therapy \& Allied Technologies 2014;23(4):206-13.

\section{Kramer 2015}

Kramer MW, Rassweiler JJ, Klein J, Martov A, Baykov N, Lusuardi L, et al. En bloc resection of urothelium carcinoma of the bladder (EBRUC): a European multicenter study to compare safety, efficacy, and outcome of laser and electrical en bloc transurethral resection of bladder tumor. World Journal of Urology 2015;33(12):1937-43.

\section{Kramer 2017}

Kramer MW, Altieri V, Hurle R, Lusuardi L, Merseburger AS, Rassweiler J, et al. Current evidence of transurethral en-bloc 
resection of nonmuscle invasive bladder cancer. European Urology Focus 2017;3(6):567-76.

\section{Liberati 2009}

Liberati A, Altman DG, Tetzlaff J, Mulrow C, Gøtzsche PC, loannidis JPA, et al. The PRISMA statement for reporting systematic reviews and meta-analyses of studies that evaluate health care interventions: explanation and elaboration. PLoS Medicine 2009;6(7):e1000100. [DOI: 10.1371/ journal.pmed.1000100]

\section{Mariappan 2010}

Mariappan P, Zachou A, Grigor KM, Edinburgh Uro-Oncology Group. Detrusor muscle in the first, apparently complete transurethral resection of bladder tumour specimen is a surrogate marker of resection quality, predicts risk of early recurrence, and is dependent on operator experience. European Urology 2010;57(5):843-9.

\section{Migliari 2015}

Migliari R, Buffardi A, Ghabin H. Thulium laser endoscopic en bloc enucleation of nonmuscle-invasive bladder cancer. Journal of Endourology 2015;29(11):1258-62.

\section{Mostofi 1973}

Mostofi FK, Sobin LH, Torloni H \& World Health Organization. Histological typing of urinary bladder tumours. World Health Organization 1973. [https://apps.who.int/iris/ handle/10665/41533]

\section{National Cancer Institute 2017}

National Cancer Institute. Common Terminology Criteria for Adverse Events (CTCAE). National Cancer Institute. accessed 25 June 2018 November 27, 2017.

\section{Review Manager 2014 [Computer program]}

Nordic Cochrane Centre, The Cochrane Collaboration. Review Manager 5 (RevMan 5). Version 5.3. Copenhagen: Nordic Cochrane Centre, The Cochrane Collaboration, 2014.

\section{Richards 2014}

Richards K, Smith ND, Steinberg GD. The importance of transurethral resection of bladder tumor in the management of nonmuscle invasive bladder cancer: a systematic review of novel technologies. Journal of Urology 2014;191(6):1655-64.

\section{Schünemann 2011}

Schünemann HJ, Oxman AD, Higgins JPT, Vist GE, Glasziou P, Guyatt GH. Chapter 11: Presenting results and 'Summary of findings' tables. In: Higgins JP, Green S, editor(s). Cochrane Handbook for Systematic Reviews of Interventions Version 5.1.0 (updated March 2011). The Cochrane Collaboration, 2011. Available from handbook.cochrane.org.

\section{Sievert 2009}

Sievert KD, Amend B, Nagele U, Schilling D, Bedke J, Horstmann M, et al. Economic aspects of bladder cancer: what are the benefits and costs?. World Journal of Urology 2009;27(3):295-300.

\section{Sobin 2009}

Sobin LH, Gospodarowicz MK, Wittekind C. TNM classification of malignant tumors. UICC International Union Against Cancer. 7 2009.

\section{Steinmaus 2014}

Steinmaus C, Ferreccio C, Acevedo J, Yuan Y, Liaw J, Durán V, et al. Increased lung and bladder cancer incidence in adults after in utero and early-life arsenic exposure. Cancer Epidemiology, Biomarkers \& Prevention 2014;23(8):1529-38.

\section{Sterne 2011}

Sterne JA, Sutton AJ, Ioannidis JP, Terrin N, Jones DR, Lau J, et al. Recommendations for examining and interpreting funnel plot asymmetry in meta-analyses of randomised controlled trials. BMJ 2011;343:d4002.

\section{Sylvester 2005}

Sylvester RJ, van der Meijden A, Witjes JA, Jakse G, Nonomura N, Cheng C, et al. High-grade Ta urothelial carcinoma and carcinoma in situ of the bladder. Urology 2005;66(6 Suppl 1):90-107.

\section{Traxer 2004}

Traxer O, Pasqui F, Gattegno B, Pearle MS. Technique and complications of transurethral surgery for bladder tumours. British Journal of Urology, International 2004;94(4):492-6.

\section{van Osch 2016}

van Osch FH, Jochems SH, van Schooten FJ, Bryan RT, Zeegers MP. Quantified relations between exposure to tobacco smoking and bladder cancer risk: a meta-analysis of 89 observational studies. International Journal of Epidemiology 2016;45(3):857-70.

\section{Vieira 2015}

Vieira R, Vingeliene S, Chan DS, Aune D, Abar L, Navarro Rosenblatt $D$, et al. Fruits, vegetables, and bladder cancer risk: a systematic review and meta-analysis. Cancer Medicine 2015;4(1):136-46.

\section{Witjes 2018}

Witjes JA, Bruins M, Cathomas R, Compérat E, Cowan NC, Gakis G, et al. EAU Guidelines on muscle-invasive and metastatic bladder cancer. EAU Guidelines 2018. EAU Guidelines Office. Arnhem, 2018.

\section{Zhang 2015}

Zhang XR, Feng C, Zhu WD, Si JM, Gu BJ, Guo H, et al. Two micrometer continuous-wave thulium laser treating primary non-muscle-invasive bladder cancer: is it feasible? A randomized prospective study. Photomedicine and Laser Surgery 2015;33(10):517-23.

\section{ADDITIONAL TABLES}


Table 1. 2017 TNM (Tumor-Node-Metastasis) classification

\begin{tabular}{llc}
\hline T - Primary tumour & N - Regional lymph nodes & $\begin{array}{l}\text { M - Distant } \\
\text { metastasis }\end{array}$ \\
\hline TX Primary tumour cannot be assessed & $\begin{array}{l}\text { Nx Regional lymph nodes cannot be as- } \\
\text { sessed }\end{array}$ & $\begin{array}{l}\text { M0 No distant } \\
\text { metastasis }\end{array}$ \\
\hline T0 No evidence of primary tumour & No No regional lymph node metastasis & $\begin{array}{l}\text { M1a Non-regional } \\
\text { lymph nodes }\end{array}$ \\
\hline Ta Non-invasive papillary carcinoma & $\begin{array}{l}\text { N1 Metastasis in a single lymph nodes in } \\
\text { the true pelvis (hypogastric, obturator, } \\
\text { external iliac, or presacral) }\end{array}$ & metastases \\
\hline
\end{tabular}

Tis Carcinoma in situ: "flat tumour"

N2 Metastasis in multiple regional lymph nodes in the true pelvis (hypogastric, obturator, external iliac, or presacral)

T1 Tumour invades subepithelial connective tissue N3 Metastasis in common iliac lymph node(s)

T2 Tumour invades muscle

T2a Tumour invades superficial muscle (inner half)

T2b Tumour invades deep muscle (outer half)

T3 Tumour invades perivesical tissue

T3a Microscopically

T3b Macroscopially (extravesical mass)

T4 Tumour invades any of the following: prostate stroma, seminal vesicles, uterus, vagina, pelvic wall, abdominal wall

T4a Tumour invades prostate stroma, seminal vesicles, uterus or vagina

T4b Tumour invades pelvic wall or abdominal wall

2016 TNM classification approved by the Union International Contre le Cancer (UICC) (Brierley 2017)

\section{APPENDICES}

\section{Appendix 1. Draft search strategy}

If we detect additional relevant keywords during any of the electronic or other searches, we will modify the electronic search strategies to incorporate these terms and will document the changes.

\section{CENTRAL}

1. bladder cancer

2. bladder neoplasms

3. bladder tumor 
4. bladder tumour

5. \#1 or \#2 or \#3 or \#4

6. en-bloc

7. en bloc

8. \#6 or \#7

5. \#5 and \#8

\section{MEDLINE (via PubMed/OVID)}

bladder cancer AND en-bloc

1. bladder cancer

2. bladder neoplasms

3. bladder tumor

4. bladder tumour

5. 1 or 2 or 3 or 4

6. en-bloc

7. en bloc

8. 6 or 7

9. (randomised controlled trial.pt. or controlled clinical trial.pt.or randomized.ab. or placebo.ab. or clinical trials as topic.sh. or randomly.ab. or trial.ti.) not (animals.sh not (humans.sh and animals.sh))

10.5 and 8 and 9

\section{Embase (via OVID)}

bladder cancer AND en-bloc

1. bladder cancer

2. bladder neoplasms

3. bladder tumor

4. bladder tumour

5. or /1-4

6. en-bloc

7. en bloc

8. or/6-7

9. ((RANDOMIZED-CONTROLLED-TRIAL/ or RANDOMIZATION/ or CONTROLLEDSTUDY/ or MULTICENTER-STUDY/ or PHASE-3-CLINICAL-TRIAL/ or PHASE-4- CLINICAL-TRIAL/ or DOUBLE-BLIND-PROCEDURE/ or SINGLE-BLIND-PROCEDURE/) or ((SINGL* or DOUBL* or TRE$\mathrm{BL}^{*}$ or TRIPL*) adj3 (BLIND* or MASK$\left.\left.{ }^{\star}\right)\right)$ ).ti,ab) not (animals.sh not (humans.sh and animals.sh))

10. 5 and 8 and 9

\section{Scopus}

bladder cancer or bladder neoplasms or bladder tumor or bladder tumour AND en-bloc or en bloc

\section{Google Scholar}

bladder cancer or bladder neoplasms or bladder tumor or bladder tumour AND en-bloc or en bloc

En-bloc resection versus conventional transurethral resection for patients with non-muscle-invasive bladder cancer (Protocol) 


\section{Web of Science}

TOPIC: bladder cancer AND TOPIC: en-bloc

\section{ClinicalTrials.gov}

bladder cancer or bladder neoplasms or bladder tumor or bladder tumour AND en-bloc or en bloc

World Health Organization (WHO) International Clinical Trials Registry Platform (ICTRP) search portal

bladder cancer or bladder neoplasms or bladder tumor or bladder tumour AND en-bloc or en bloc

\section{CONTRIBUTIONS OF AUTHORS}

Kim van Putten (KvP): wrote the protocol.

Xiaoye Zhu (XZ): wrote the protocol.

Robin WM Vernooij (RV): wrote the protocol.

Richard P Meijer (RM): wrote the protocol.

All review authors read and approved the final protocol version.

\section{DECLARATIONSOF INTEREST}

KvP has no known conflicts of interest.

XZ has no known conflicts of interest.

RV has no known conflicts of interest.

RM has no known conflicts of interest.

\section{SOURCES OF SUPPORT}

\section{Internal sources}

- Urology, Cancer Center, UMC Utrecht, Utrecht, Netherlands.

- Urology, Radboud University Medical Center, Nijmegen, Netherlands.

- Nephrology \& Julius Centre, UMC Utrecht, Utrecht, Netherlands.

\section{External sources}

- No sources of support supplied 